Review Article

\title{
Analysis of the Relationship between Type II Diabetes Mellitus and Parkinson's Disease: A Systematic Review
}

\author{
Fauze Camargo Maluf $\left(\mathbb{D},{ }^{1}\right.$ David Feder $\mathbb{D}{ }^{2}$ and Alzira Alves de Siqueira Carvalho $\mathbb{D}^{3}$ \\ ${ }^{1}$ Medical Student of Centro Universitario Saude ABC, Centro Universitario Saude ABC, FMABC, Santo Andre 09060-870, Brazil \\ ${ }^{2}$ Department of Pharmacology, Centro Universitario Saude ABC, FMABC, Santo Andre 09060-870, Brazil \\ ${ }^{3}$ Department of Neurosciences, Centro Universitario Saude ABC, FMABC, Santo Andre 09060-870, Brazil \\ Correspondence should be addressed to Fauze Camargo Maluf; fauzecamargo@hotmail.com
}

Received 1 May 2019; Revised 1 October 2019; Accepted 6 November 2019; Published 23 November 2019

Academic Editor: Hélio Teive

Copyright (C) 2019 Fauze Camargo Maluf et al. This is an open access article distributed under the Creative Commons Attribution License, which permits unrestricted use, distribution, and reproduction in any medium, provided the original work is properly cited.

\begin{abstract}
In the early sixties, a discussion started regarding the association between Parkinson's disease (PD) and type II diabetes mellitus (T2DM). Today, this potential relationship is still a matter of debate. This review aims to analyze both diseases concerning causal relationships and treatments. A total of 104 articles were found, and studies on animal and "in vitro" models showed that T2DM causes neurological alterations that may be associated with PD, such as deregulation of the dopaminergic system, a decrease in the expression of peroxisome proliferator-activated receptor-gamma coactivator-1 $\alpha(P G C-1 \alpha)$, an increase in the expression of phosphoprotein enriched in diabetes/phosphoprotein enriched in astrocytes 15 (PED/PEA-15), and neuroinflammation, as well as acceleration of the formation of alpha-synuclein amyloid fibrils. In addition, clinical studies described that Parkinson's symptoms were notably worse after the onset of T2DM, and seven deregulated genes were identified in the DNA of T2DM and PD patients. Regarding treatment, the action of antidiabetic drugs, especially incretin mimetic agents, seems to confer certain degree of neuroprotection to PD patients. In conclusion, the available evidence on the interaction between T2DM and PD justifies more robust clinical trials exploring this interaction especially the clinical management of patients with both conditions.
\end{abstract}

\section{Introduction}

The prevalence of type 2 diabetes mellitus (T2DM) is 370 million people in the world. The T2DM is most frequent in adulthood; however, in the last years, the prevalence of $\mathrm{T} 2 \mathrm{DM}$ is increasing in adolescents and children $[1,2]$. T2DM is a chronic metabolic disease characterized by longterm insulin resistance and a decrease of $\beta$-cell function and population. These factors impair insulin release and consequently cause hyperglycemia $[3,4]$. However, genetic and environmental factors are responsible for $20 \%$ of $\beta$-cell failure in the diabetic population [2].

One of the consequences of chronic diabetes is the production of toxic aggregates of the islet amyloid polypeptide (IAPP). The IAPP might contribute to $\beta$-cell dysfunction [5].
Parkinson's disease (PD) affects about $1 \%$ of people over 65 and up to $4-5 \%$ of people over 85 , and thus it represents the second most common neurodegenerative disorder $[6,7]$.

The diagnosis of PD is still based on the presence of symptoms and clinical signs such as typical asymmetric manifestation, the most common finding being tremor at rest in the upper limbs associated with bradykinesia, rigidity, and gait difficulty [8].

The etiology of PD is based on the combination of genetic ( $10 \%$ of cases) and probably environmental factors [9]. Moreover, most of PD cases are idiopathic, and the exact etiology is still unclear [7].

The concept of protein misfolding disorder (PMD) is relevant for the understanding of the potential association of T2DM and PD. Protein misfolding disorders (PMD) are diseases caused by a protein or peptide that has been 
misfolded, aggregated, and accumulated in certain tissues. There are at least 30 different PMDs, including neurodegenerative, systemic, and metabolic disorders such as PD and T2DM [10].

The specific protein that misfolds and could contribute to the pathogenesis of T2DM is called amylin. This protein is deposited as aggregates and has been found in the pancreas and brain tissue [5].

Human alpha-synuclein is the protein that misfolds and is thought by many to be related to the development of PD [11]. It is encoded by the alpha-synuclein gene (SNCA) and is expressed in neurological tissues and extraneurological tissues such as the pancreas [11]. The SNCA gene is associated with glucose and insulin regulation through K-channel modulation in $\beta$ cells of the pancreas $[12,13]$ responsible for aggregation, toxicity, and $\mathrm{Ca}^{2+}$ binding [14].

In $\mathrm{PD}$, there is the aggregation, deposition, and dysfunction of alpha-synuclein, which causes the accumulation and propagation of alpha-synuclein to various brain regions and cellular populations [15]. The levels of alphasynuclein depend on the proportion between the synthesis, aggregation, and clearance of alpha-synuclein. A dysfunction in this proportion may result in high levels of alpha-synuclein that might favor the formation of toxic species [16]. Therefore, it is not unlikely that the two proteins, amylin and alpha-synuclein, would affect each other in vivo, causing T2DM and PD [17]. In addition, recent discoveries have showed common pathways that probably relate neurodegenerative mechanisms with abnormal glucose metabolism and abnormal mitochondrial function [18].

The association between T2DM and PD was previously reported since patients with $\mathrm{T} 2 \mathrm{DM}$ seem to have an increased risk of also developing PD [19]. In a large cohort of 8 million people, Pablo-Fernandez et al., [20] showed a higher rate of subsequent PD following T2DM. However, there are studies that showed the opposite or no relation between these diseases $[21,22]$.

Another point suggesting a possible correlation between PD and T2DM has been demonstrated in the interaction of hypoglycemic and antiparkinsonian drugs. The recent studies took into account the effects of some drugs used to treat PD, such as levodopa, which induces both hyperglycemia and hyperinsulinemia [23], whereas others (including the ergot dopamine agonist bromocriptine) may increase insulin sensitivity [24]. In addition, hypoglycemic drugs such as biguanide [25], sulfonylureas [26], thiazolidinediones [27], and incretinomimetics [28] were used in the management of patients with PD.

T2DM and PD are common diseases that negatively affect patients' quality of life. Thus, it is of utmost importance not only to study these diseases in an isolated manner but also to investigate their correlations and interactions. So, this review aims to assess the risk factor association, the genetic link and the pathophysiologic interactions between T2DM and PD. Moreover, this review intends to determine the modifications on the clinical features when these diseases are associated and to evaluate
TABle 1: Relations of descriptors and studies found in PubMed database.

\begin{tabular}{lc}
\hline Descriptors & $\begin{array}{c}\text { Number of } \\
\text { articles }\end{array}$ \\
\hline Parkinson's disease $\times$ diabetes mellitus & 335 \\
Parkinson's disease $\times$ insulin resistance & 39 \\
Alpha-synuclein $\times$ diabetes mellitus & 19 \\
Alpha-synuclein $\times$ insulin resistance & 5 \\
Islet amyloid polypeptide $\times$ Parkinson's disease & 5 \\
Metformin $\times$ Parkinson's disease & 9 \\
Sulfonylurea $\times$ Parkinson's disease & 16 \\
Thiazolidinediones $\times$ Parkinson's disease & 19 \\
GLP-1 $\times$ Parkinson's disease & 7 \\
Bromocriptine $\times$ diabetes mellitus & 98 \\
Exenatide $\times$ Parkinson's disease & 19 \\
Levodopa $\times$ diabetes mellitus & 54 \\
Dipeptidyl-peptidase IV inhibitors $\times$ Parkinson's & 2 \\
disease & \\
Sodium-glucose transporter 2 & 0 \\
inhibitors $\times$ Parkinson's disease & \\
\hline
\end{tabular}

the impact of hypoglycemic drugs on $\mathrm{PD}$ and antiparkinsonian drugs on T2DM.

\section{Materials and Methods}

The review was based on the analysis of studies retrieved via PubMed up to September, 2019. Articles were screened according to the following eligibility criteria: original articles describing the relationship between PD and T2DM, unrelated to any other disease, using in vivo (human and animal) and in vitro models. The descriptors using the $\mathrm{MeSH}$ database were as follows: "("Parkinson Disease"[Mesh]) AND "Diabetes Mellitus"[Mesh]," “("Parkinson Disease"[Mesh]) AND "Insulin Resistance"[Mesh]," “("alpha-Synuclein”[Mesh]) AND "Diabetes Mellitus"[Mesh]," “("alpha-Synuclein”[Mesh]) AND "Insulin Resistance"[Mesh]," "("Islet Amyloid Polypeptide"[Mesh]) AND "Parkinson Disease"[Mesh]," "("Metformin"[Mesh]) AND "Parkinson Disease"[Mesh]," "("Sulfonylurea Compounds"[Mesh]) AND "Parkinson Disease"[Mesh]," “(“Thiazolidinediones"[Mesh:NoExp]) AND "Parkinson Disease"[Mesh]," "(“Glucagon-Like Peptide 1"[Mesh]) AND "Parkinson Disease"[Mesh]," “("Bromocriptine"[Mesh:NoExp]) AND “Diabetes Mellitus”[Mesh]," "("Exenatide"[Mesh:NoExp]) AND "Parkinsonian Disorders”[Mesh]," “(“Levodopa”[Mesh]) AND “Diabetes Mellitus"[Mesh]," “(“Dipeptidyl-Peptidase IV Inhibitors”[Mesh]) AND "Parkinson Disease"[Mesh]", "("Sodium-Glucose Transporter 2 Inhibitors"[Mesh]) AND "Parkinson Disease"[Mesh]." Letters, reviews, and articles in languages other than English were excluded.

\section{Results}

A total of 627 articles were found (Table 1). Among them, 96 were duplicated in searches with different descriptors, leaving 531 abstracts to be evaluated. Then, 157 articles were set aside to be fully read, from which 104 were used in the bibliography (Figure 1). 


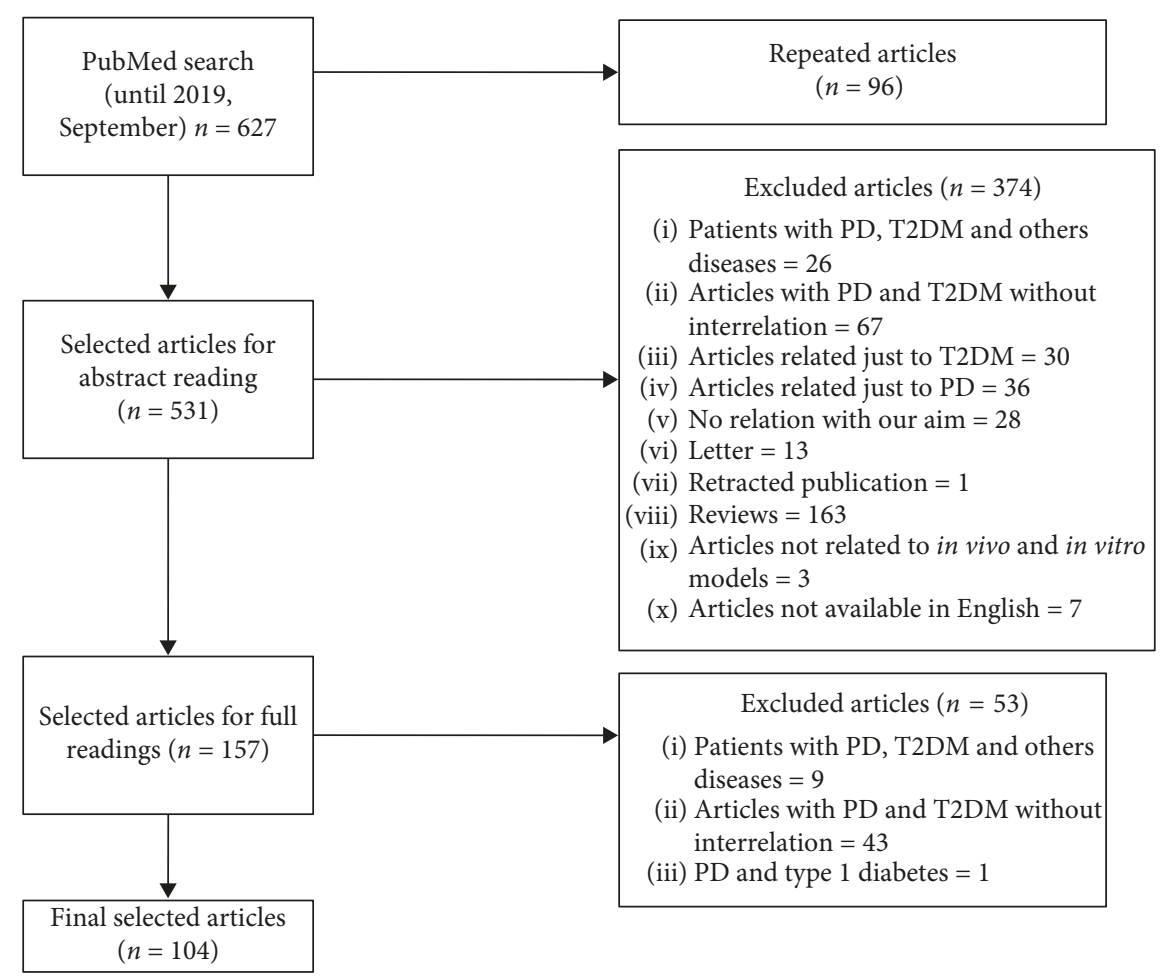

Figure 1: Flow diagram of literature search to identify articles evaluating the relationship between T2DM and PD.

Our study showed connections between PD and T2DM in relation to epidemiology (Table 2), genetics (Table 3), clinical manifestations (Table 4) and treatment (Tables 5 and 6). We also found a relationship between both conditions in the pathophysiological mechanisms. In PD, mitochondrial dysfunction [29], mutations in different genes encoding alpha-synuclein, PINK-1 (PTEN-induced putative kinase 1), and DJ-1 (Protein deglycase) may favor the development of T2DM $[12,30]$. Similarly, pathways of T2DM may influence the development of PD such as metabolic inflammation [31], downregulation of dopamine in the nigrostriatal pathway [32-34], long-term hyperglycemia [35], decrease in the expression of $P G C-1 \alpha$ (peroxisome proliferator-activated receptor-gamma coactivator-1 $\alpha$ ) [36-39], increase in the expression of PED/PEA-15 (phosphoprotein enriched in diabetes/phosphoprotein enriched in astrocytes 15 protein) [40], increased methylglyoxal levels [41, 42], and the formation of alpha-synuclein amyloid fibrils [17].

\section{Discussion}

4.1. Type 2 Diabetes vs. Parkinson's Disease: Epidemiology. The prevalence of T2DM patients suffering from $\mathrm{PD}$ is slightly heterogeneous, ranging between 3.4 and 9.1\% [123], whereas in the general population the prevalence of PD is 12 per 1000 [124]. In this review, several studies suggested that T2DM might increase the risk of developing PD $[19,20,43-49]$. This might possibly be explained due to the fact that both diseases share common pathophysiological pathways, such as increased iron levels $[125,126]$ that may be involved in the insulin regulation in the nigrostriatal pathway [32] and low expression of $P G C-1 \alpha$ gene that could lead to mitochondrial dysfunction $[18,29]$. However, there are some studies that supported an inverse association [50-54] or the lack of association [22, 55-57] between them. These conflicting findings could possibly be explained by factors like self-reported T2DM diagnosis [55] and study design (case-control studies) [22, 50-54] when the temporal relationship between disease onset and exposure is not clear. Additionally, a recent cohort with a sample size of approximately 8 million subjects indicated T2DM as a risk factor for PD [20]. This study excluded patients with cerebrovascular disease and drug-induced and vascular Parkinsonism which were not considered in previous studies [20].

As for the inverse association, PD patients less frequently suffer from T2DM owing to the decrease in sympathetic activity caused by PD [59] and the use of L-dopa, a drug that increases glycogenolysis and inhibits the use of peripheral glucose $[58,59,127]$. Only one study showed a higher chance for the development of T2DM in PD patients [60]. A possible explanation for this is the abnormal tolerance to glucose in approximately half of the patients with PD [128] that could evolve to T2DM.

Many factors related to lifestyle and genetics are interconnected with the risks of T2DM and PD. Advanced age is the main risk factor for developing PD [129] and an important factor for the onset of T2DM [130]. Interestingly, it was observed that smoking increased the risk of T2DM and reduced the risk of PD [131].

4.2. Type 2 Diabetes vs. Parkinson's Disease: Genetics. PD and T2DM are complex, multifactorial disorders with a 
TABLE 2: Trials correlating PD and T2DM as a risk factor.

\begin{tabular}{|c|c|c|}
\hline Risk of PD in patients with T2DM & Authors & Sample \\
\hline \multirow[t]{16}{*}{ Increased $(n=9)$} & De Pablo-Fernandez et al. [20] & $\begin{array}{c}\text { T2DM: } 2,017,115 \\
\text { Controls: } 6,173,208\end{array}$ \\
\hline & \multirow[b]{2}{*}{ De Pablo-Fernandez et al. [43] } & PD: 79 (14 with T2DM) \\
\hline & & Controls: 4.919 (842 with T2DM) \\
\hline & \multirow{2}{*}{ Yang et al. [44] } & T2DM: 36.294 (550 with PD) \\
\hline & & Controls: 108.882 (1232 with PD) \\
\hline & Yue et al. [45] & PD: 6441 \\
\hline & \multirow{2}{*}{ Sun et al. [46] } & T2DM: 603.413 (1.613 with PD) \\
\hline & & Controls: 472.718 (809 with PD) \\
\hline & \multirow{2}{*}{ Wahlqvist et al. [47] } & T2DM: 64.166 \\
\hline & & Controls: 698.587 \\
\hline & \multirow{2}{*}{ Schernhammer [48] } & PD: 1.931 (126 with T2DM) \\
\hline & & Controls: 9.651 (482 with T2DM) \\
\hline & \multirow{2}{*}{ Xu et al. [49] } & T2DM: 21.611 (172 with PD) \\
\hline & & Controls: 267.051 (1393 with PD) \\
\hline & \multirow{2}{*}{ Hu et al. [19] } & T2DM: 1.098 (24 with PD) \\
\hline & & Controls: 50.454 (609 with PD) \\
\hline \multirow{9}{*}{ Decreased $(n=5)$} & \multirow{2}{*}{ Miyake et al. [50] } & PD: 249 (10 with T2DM) \\
\hline & & Controls: 368 (39 with T2DM) \\
\hline & \multirow{2}{*}{$\mathrm{D}^{\prime}$ Amelio et al. [51] } & PD: 318 (13 with T2DM) \\
\hline & & Controls: 318 (31 with T2DM) \\
\hline & \multirow{2}{*}{ Leibson et al. [52] } & PD: 197 (18 with T2DM) \\
\hline & & Controls: 197 (24 with T2DM) \\
\hline & \multirow{2}{*}{ Powers et al. [53] } & PD: 352 (26 with T2DM) \\
\hline & & Controls: 484 (61 with T2DM) \\
\hline & Herishanu et al. [54] & $\begin{array}{c}\text { PD: } 93 \text { (11 with T2DM) } \\
\text { Controls: } 93 \text { (26 with T2DM) }\end{array}$ \\
\hline \multirow{7}{*}{ Not related $(n=4)$} & \multirow{2}{*}{ Savica et al. [22] } & PD: 196 (13 with T2DM) \\
\hline & & Controls: 196 (17 with T2DM) \\
\hline & Palacios et al. [55] & $\begin{array}{c}\text { PD: } 656 \\
\text { Controls: } 147,440\end{array}$ \\
\hline & \multirow{2}{*}{ Driver et al. [56] } & PD: 556 \\
\hline & & Controls: 21.285 \\
\hline & \multirow{2}{*}{ Simon et al. [57] } & PD: 530 (37 with T2DM) \\
\hline & & Controls: 171.349 (3.722 with T2DM) \\
\hline \multicolumn{3}{|l|}{ Risk of T2DM in patients with PD } \\
\hline \multirow[t]{3}{*}{ Decreased $(n=2)$} & Becker et al. [58] & PD: 3.637 (291 with T2DM) \\
\hline & \multirow{2}{*}{ Scigliano et al. [59] } & $\begin{array}{l}\text { Controls: } 3.63 \text { ( } 308 \text { with } 12 \mathrm{DM} \text { ) } \\
\text { PD: } 178 \text { (6 with T2DM) }\end{array}$ \\
\hline & & Controls: 534 (58 with T2DM) \\
\hline \multirow{2}{*}{ Increased $(n=1)$} & \multirow{3}{*}{ Pressley et al. [60] } & PD: 791 (235 with T2DM) \\
\hline & & Controls: 24.040 (5.175 with T2DM) \\
\hline Total $=21$ & & \\
\hline
\end{tabular}

TABLE 3: Trials correlating genetic profile and T2DM/PD.

\begin{tabular}{lcc}
\hline Authors & Sample (controls/PD/T2DM) & Correlation between T2DM and PD \\
\hline Chung et al. [61] & $500 / 500 / 102$ & No correlation \\
Santiago et al. [62] & $46 / 50 / 10$ & 84 genes \\
Santiago et al. [63] & $91 / 101 / 11$ & 478 genes \\
& & 7 genes (microarray) \\
\hline
\end{tabular}

combination of environmental and genetic factors involved in the pathogenesis of the diseases. PD and T2DM with genetic alterations represent $5-10 \%$ of cases [132].

The genetic relationship between these diseases was confirmed by genetic mapping of the genes in both diseases.
In this study, a genome-wide association study (GWAS) and microarrays showed 478 genes closely associated with confirmed PD and T2DM [63]. In a different study, using only GWAS, $84 \mathrm{PD}$, and T2DM-associated genes were identified [62]. Therefore, it is believed that genes associated 
TABLE 4: Trials correlating clinical features of patients with PD and T2DM.

\begin{tabular}{lcc}
\hline Influence of T2DM on PD & Authors & PD with T2DM/PD without T2DM \\
\hline Major cognitive impairment $(n=3)$ & Ong et al. [65] & PD with T2DM: 11 \\
PD without T2DM: 51 & PD with T2DM: 12 \\
PD without T2DM: 24 & PD with T2DM: 15 \\
& Petrou et al. [66] & PD without T2DM: 133 \\
\hline $\begin{array}{l}\text { Worsening of motor symptoms and/or postural } \\
\text { instability }(n=4)\end{array}$ & Bohnen et al. [67] & PD with T2DM: 25 \\
& Pohamed Ibrahim et al. [68] & PD with T2DM: 21 \\
& Pagano et al. [69] & PD without T2DM: 51 \\
& PD with T2DM: 13 \\
& Potagal et al. [70] & PD without T2DM: 26 \\
& Cereda et al. [71] with T2DM: 466 \\
$\begin{array}{l}\text { Influence of PD on T2DM } \\
\begin{array}{l}\text { Reduction of glycemia and/or glycated hemoglobin } \\
\text { and lipid profile improvement }(n=1)\end{array}\end{array}$ & Pch without T2DM: 921 \\
\hline
\end{tabular}

TABle 5: Protection of anti-Parkinson's drugs in T2DM.

\begin{tabular}{lr}
\hline LEVODOPA & BROMOCRPTINE \\
\hline No & Yes \\
Human trials: Cereda et al. [71], Rosati et al. [73] & Roe et al. [75], Ghosh et al. [76], Gaziano et al. [77], \\
& Vinik et al. [78], Pijl et al. [79] \\
& Animal studies: Ezrokhi et al. [80], Luo et al. [81], \\
& Luo et al. [82], Cincotta et al. [83] \\
\hline
\end{tabular}

with T2DM can be used to identify PD genes, and the PD genes can identify T2DM genes, as well [63]. However, in another study, the GWAS analysis of PD and T2DM did not reveal any significant relationship between the diseases [61]. This fact could be explained because the authors exclusively analyzed the top candidate variants which precluded to find rare genetic variants or copy-number variations [61].

Moreover, T2DM and PD patients have a common haplogroup, B5b [64], indicating that they share same genetic mutations in mitochondrial DNA (mtDNA), such as the presence of the adenine in position 709 of the mtDNA (709G $>A)$. The mitochondrial dysfunction present in both pathologies could therefore be explained by this finding $[77,133]$

Finally, in microarray analyses, seven deregulated genes, the amyloid precursor protein $(A P P)$ gene in particular, were quantified by gene expression from blood samples of T2DM and PD patients [63]. Actually, the expression of APP is increased in PD and prediabetic patients [134, 135], suggesting that high levels of the protein encoded by this gene in the blood of T2DM patients could be an indicator of neurodegeneration $[63,136]$.

4.3. Type 2 Diabetes vs. Parkinson's Disease: Clinical Manifestations. Patients with both T2DM and PD have a noticeable aggravation of motor symptoms, higher degree of cognitive impairment and earlier onset of complications $[65-69,71]$. Regarding motor symptoms, the worsening was especially observed in the postural instability and mobility of these patients [69-71], whereas attention impairment and slower speed of thinking were noted in the cognitive processes $[65,67]$. Such damages may be associated with dopamine regulation deficiency and neuroinflammation [31-34], confirmed by image tests that showed white matter injuries, lacunar infarctions and cortical atrophy in T2DM patients $[137,138]$. Moreover, motor complications (motor fluctuations and dyskinesia) happened one year earlier compared with subjects with only PD [68]. Therefore, longer periods of hospitalization, as well as daily care, are typically required for these patients [72].

In addition, the risk of cerebrovascular accident (CVA) in patients with T2DM and PD is higher than in those with T2DM only [72]. A possible reason for this higher incidence is the fact that PD patients have increased levels of homocysteine due to the use of L-dopa increasing the synthesis of free radicals and enhancing neuroinflammation [139].

Patients with PD and T2DM showed a reduction in $\mathrm{HbA} 1 \mathrm{c}$ and an improvement in the lipid profile [72]. The use of drugs for the treatment of PD, bromocriptine in particular, as well as the reduction in the sympathetic activity and hypothalamic-pituitary-adrenal axis impairment [59] would probably decrease the production of catecholamines and cortisol resulting in lower levels of glycemia [59]. Concerning the improvement in the lipid profile, no relevant hypothesis has yet been made. One possible explanation is the fact that dyskinesia and 
TABle 6: Protection of antidiabetic drugs in PD.

METFORMIN

Yes

No

Yes

Animal studies: Katila et al. [25], Ryu et al.

[84], Ismael et al. [85], Patil et al. [86], Choi et al. [87]

Human trials: Kuan et al. [88]

Cell culture studies: Fitzgerald et al. [89]

GLP-1 Agonist (Exenatide/Liraglutide/

Semaglutide)

Yes

Animal studies: Zhang et al. [90], Bassil et al.

[27], Cao et al. [91], Hansen et al. [92], Kim

et al. [93], Li et al. [94], Bertilsson et al. [95],

Harkavyi et al. [96]

GIP Agonist (D-Ala2-GIP-glu-PAL)

Yes

Animal studies: Feng et al. [102], Li et al.

[103]

DPP-4 Inhibitors

Yes

Yes

Human trials: Athauda et al. [97], Bassil et al. [90], Aviles-Olmos et al. [98], AvilesOlmos et al. [99]

\section{Yes}

Cell culture studies: Jalewa et al. [100], Perry et al. [101]

\section{Yes}

Cell culture studies: Jalewa et al. [100]

Animal studies: Abdelsalam et al. [104], Pipatpiboon et al. [105]

\section{Sulphonylurea}

No

Animal studies: Obata et al. [26], Kou et al. [107]
Thiazolidinediones

Yes

Animal studies: Pinto et al. [28], Martinez et al. [109] Ren et al. [110], Barbiero et al. [111], Pisanu et al. [112], Quinn et al. [113], Hunter et al. [114], Dehmer et al. [115], Breidert et al. [116]
No

Human trials: Wahlqvist et al. [47]
No

Cell culture studies: Tai et al. [108]

Human trials: Svenningsson et al. [106]

No consensus $\quad$ Yes

Human trials: Brakedal et al. [117], Brauer

et al. [118], Ninds Exploratory trials in Cell culture studies: Jung et al. [121], Xing Parkinson's disease FS-ZONE, Investigators et al. [119], Simon et al. [120]

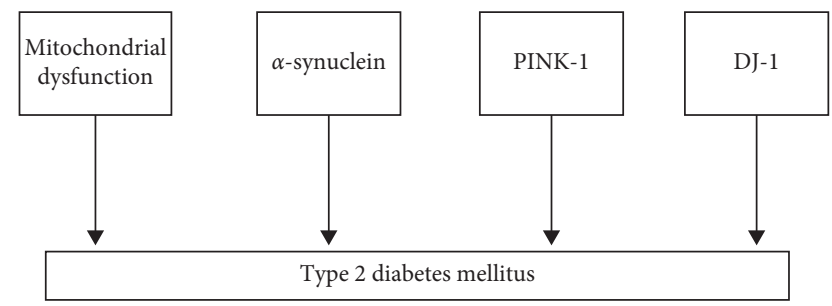

Figure 2: Pathophysiological mechanism of PD that may favor the development of T2DM.

decreased physical activity observed in some PD patients may lead to less food intake, which could reduce the lipid level [140]. However, more studies are necessary to explore the potential pathophysiology of better levels of lipid in PD and T2DM patients.

4.4. Type 2 Diabetes vs. Parkinson's Disease: Pathophysiology. Based on results of "in vitro" studies and studies using animal models, this review suggests that there are common pathophysiological features involving T2DM and PD (Figures 2 and 3 ).

Many studies suggested pathophysiological mechanisms already related to PD that may favor the development of T2DM such as mitochondrial dysfunction [29], mutations in

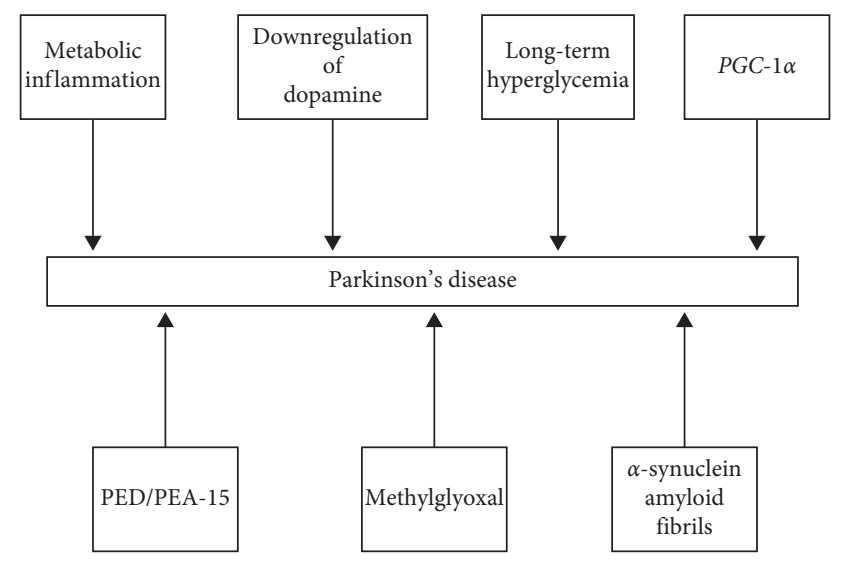

FIgURE 3: Pathophysiological mechanism of T2DM that may favor the development of PD.

genes encoding alpha-synuclein, PINK-1 (PTEN-induced putative kinase 1), and DJ-1 (Protein deglycase) $[12,30]$.

The neuroinflammatory processes observed in PD activate microglia cells, causing the overproduction of reactive oxygen species (ROS) and proinflammatory cytokines (nitrous oxide and tumor necrosis factor-alpha) with resulting mitochondrial dysfunction [141].

To simulate the mitochondrial dysfunction in PD, many studies used the neurotoxin 1-methyl-4-phenyl-1,2,3,6- 
tetrahydropyridine (MPTP). This drug mimics PD-like symptoms and inhibits complex I of the respiratory chain [142-144] by decreasing ATP production and triggering the release of free radicals, thus leading to the death of dopaminergic neurons [29]. The mitochondrial dysfunction caused by PD may accelerate the progression of insulin resistance via increased production of ROS [145]. Therefore, it is possible that the mitochondrial dysfunction observed in PD could promote the development of T2DM.

In relation to mutations in gene-encoding proteins, studies using alpha-synuclein in rats showed that this protein lowers the resistance to insulin [12]. In PD, the mutated alpha-synuclein could trigger the formation of aggregates of the protein [146], thus impairing insulin resistance and increasing the likelihood of developing T2DM [147].

Moreover, the deficiency of DJ-1 inhibits the aggregation of alpha-synuclein and increases the resistance to insulin in rats [148]. Likewise, PINK-1 deficiency, present in PD, also favors resistance to insulin [30]. Hence, mutations of alphasynuclein, DJ-1, and PINK-1 are important related factors that may favor the development of T2DM in PD patients.

On the other hand, we also found pathophysiological components of T2DM that could lead to PD such as metabolic inflammation [31], downregulation of dopamine in the nigrostriatal pathway [32-34], long-term hyperglycemia condition [35], decrease in the expression of $P G C-1 \alpha$ (peroxisome proliferator-activated receptor-gamma coactivator-1 $\alpha$ ) [36-39], increase in the expression of PED/PEA15 (phosphoprotein enriched in diabetes/phosphoprotein enriched in astrocytes 15 protein) [40], increased methylglyoxal levels [41, 42], and the formation of alpha-synuclein amyloid fibrils [17].

Many studies evaluated the use of MPTP in diabetic rats to analyze the pathophysiological interaction between both diseases. The use of MPTP in diabetic rats resulted not only an accelerated loss of dopaminergic neurons and the activation of glial cells in the substantia nigra but also an increase in the activation of inflammatory molecules, including NLRP3 and alpha-synuclein aggregates in the pancreas and in the brain. In addition, the endoplasmic reticulum stress markers CHOP and GRP78 were positively regulated in the pancreas, liver, and brain of mice with T2DM [31]. Therefore, the metabolic inflammation in T2DM may contribute to the occurrence of PD.

Futhermore, it was observed that insulin regulates dopamine synthesis and uptake within the substantia nigra [34]. Some studies have revealed that the impaired insulin signaling in T2DM causes the degeneration of the nigrostriatal dopaminergic pathway and an exacerbated neurodegeneration in animals [32-34] that consequently could facilitate the onset of PD-like symptoms. In addition, longterm hyperglycemia in a rat model also caused nigrostriatal dopaminergic neurodegeneration due to elevated basal oxidative burden and motor impairments that are similar to early parkinsonian symptomatology [35].

In insulin resistance, the gene $P G C-1 \alpha$, a regulator of enzymes involved in mitochondrial respiration, shows reduced expression $[36,39]$. Additionally, $P G C-1 \alpha$ is repressed by PARIS (ZNF746), a protein that causes neurodegeneration in $\mathrm{PD}$ due to parkin inactivation [37]. Many researchers observed that $P G C-1 \alpha$ protects against the destruction of dopaminergic neurons [37, 38]. As a consequence, the decreased protection of these neurons in T2DM may lead to the development of PD.

Another pathophysiological mechanism in T2DM is the protein PED/PEA-15. This protein is increased in many cells (skeletal muscles, adipocytes, skin fibroblasts, and peripheral blood leukocytes) in T2DM patients. A recent study showed that rats overexpressing this protein had a reduction in dopaminergic activity, a fact that may induce the development of PD [40].

One recent association between $\mathrm{PD}$ and $\mathrm{T} 2 \mathrm{DM}$ is the ADTIQ (1-acetyl-6,7-dihydroxy-1,2,3,4-tetrahydroisoquinoline) and its precursor methylglyoxal (a subproduct of glucose metabolism that is increased in diabetic patients) [149]. ADTIQ was recently discovered in frozen human PD brain tissues [150], and its role could be as an endogenous neurotoxin that causes PD [151]. In diabetic rats, it was observed that the accumulation of ADTIQ, produced by the reaction of dopamine and methylglyoxal, caused neuronal injury, oxidative stress, and apoptosis [41, 42]. Therefore, it is possible that ADTIQ may be an important factor to increase the risk of $\mathrm{PD}$ in patients with T2DM.

Finally, the formation of alpha-synuclein aggregates can be observed in PD, whereas pancreatic amyloid plaques formed by the pancreatic islet amyloid polypeptide (IAPP) are present in T2DM. In one study, it was noted that the speed of alpha-synuclein aggregation is higher when it interacts with IAPP [17], thus showing an increased propensity for the development of PD in T2DM cases. A possible explanation could be the excessive glycation process in T2DM patients. In this process, proteins undergo posttranslational modification, which affects the alpha-synuclein structure and increases its aggregation [152].

\subsection{Type 2 Diabetes vs. Parkinson's Disease: Treatment Related Issues}

4.5.1. Antidiabetic Drugs. Biguanides (metformin) activate the AMP-activated kinase protein (AMPK) [153] responsible for the homeostatic control of cellular energy balance, glucose absorption in the muscle, and the inhibition of hepatic glucose production [154]. In rodent models, these properties neutralize the toxicity of MPTP through the reduction of oxidative stress levels [155], the neurogenic potential of this drug [156], and the restoration of the mitochondrial membrane potential [89]. Metformin also was associated with neuroprotection by ameriolating the neurotoxicity of alpha-synuclein in human neuroblastoma SH-SY5Y cells [157]. Futhermore, two studies observed the neuroprotection of metformin through the improvement in the motor function of the animals $[25,84,86]$. Nevertheless, one study showed an increased risk of PD associated with the use of metformin in a mouse model [85]. In human trials, metformin was usually combined with other antidiabetic drugs such as sulphonylureas [47] and thiazolidinediones 
[117]. Only one trial studied metformin individually and found a higher incidence of PD [88]. The increased risk of PD could be explained by the elevation of AMP/ATP and $\mathrm{ADP} / \mathrm{ATP}$ ratios that occurs through the activation of AMPK, with inhibition of the mitochondrial complex I and, as a result, an increase in vulnerability as well as degeneration of dopaminergic neurons [85]. The effect of metformin in patients with PD has not been fully elucidated. Therefore, the potential benefit or harm of metformin in patients with PD remains to be determined.

Sulphonylureas (glibenclamide, tolbutamine, and glipizide) stimulate insulin release by inhibiting the ATP-sensitive $\mathrm{K}+$ (K ATP) channel of pancreatic beta-cells resulting in the closure of the potassium channels and opening of calcium channels [158]. However, these channels are present not only in the pancreas but also in cardiac, skeletal cells, and in neurons of the central nervous system (cortex, basal ganglia, hippocampus, hypothalamus, and striated muscles in particular) $[159,160]$. The activation of K ATP channels in the central nervous system has already been associated as a protector of mitochondria function [161]. Consequently, it is possible that the inhibition of K ATP channels might intensify mitochondria dysfunction and aggravates the neurological complications in PD patients [108]. Sulphonylureas did not show neuroprotection in any of the analyzed studies [26, 47, 107, 108], which could be a predisposing factor for the development of PD.

Several studies investigated the effect of thiazolidinediones (pioglitazone and rosiglitazone) in the treatment of PD [28, 109-122]. They act on peroxisome proliferatoractivated receptor-gamma (PPAR-y) receptors by boosting the action of insulin [162] and bind to the protein of the external mitochondrial membrane [163-165]. This interaction showed positive effects on the activity of complex I of the respiratory chain in neuronal cells, which can reverse mitochondrial dysfunction in PD [166]. Besides, these drugs showed a protective action against neurodegeneration and neuroinflammation in MPTP-treated rodents, triggered by either a lipopolysaccharide model or an L-dopa-induced dyskinesia model, as well as in humans [28, 109-122]. This protective property of thiazolidinediones can be explained by the activation of PPAR-y, which reduced or reversed the microglial polarity, resulting in a decrease in nitric oxide synthase (NOS) activity, oxidative stress, and free radical release $[13,115,116]$. Some studies, however, suggested the beneficial action of thiazolidinediones through the inhibition of monoamine oxidase $\mathrm{B}$ (MAO-B) preventing the breakdown of dopamine and, consequently, increasing the levels of dopamine [113]. Surprisingly, a recent 44 -week placebo-controlled phase 2 study in $210 \mathrm{PD}$ patients did not show the neuroprotective effect of this drug [119]. In addition, a different study could not identify a reduction in the biomarkers of $\mathrm{PD}$ in patients on pioglitazone, such as leukocyte $P G C-1 \alpha$, plasma interleukin 6, and urine 8-hydroxydeoxyguanosine [120]. However, it is important to underline that these biomarkers are not FDA approved. Therefore, according to these new studies, there appears to be no potential for this drug to treat $\mathrm{PD}$ neurodegeneration.
Incretin mimetics drugs (GLP-1/GIP agonists and DPP4 inhibitors) activate glucagon-like peptide-1 (GLP-1) or glucose-dependent insulinotropic polypeptide (GIP) receptors on pancreatic beta-cells stimulating insulin secretion and synthesis $[100,166]$. The activation of the GLP-1 receptor by GLP-1 agonists (exenatide, liraglutide, and semaglutide) seems to prevent the death of dopaminergic neurons and improve motor and cognitive functions [27, 90-97, 99-101, 167, 168]. These facts can be explained by the increase in levels of tyrosine hydroxylase and vesicular monoamine transporter 2 (VMAT-2) in neurons of the nigrostriatal system along with the inhibition of microglial activation and the release of proinflammatory mediators [91, 95-97]. A recent study suggested the possible neuroprotective effect of exenatide through the activation of protein kinase $\mathrm{B}(\mathrm{PKB})$ and the mitogen-activated protein kinase (MAP kinase) pathways. Together, they influence not only neuroinflammation but also neuronal and mitochondrial survival pathways [169]. Besides, a groundbreaking randomised, double-blind, placebo-controlled trial demonstrated that PD patients treated with exenatide once in a week for 48 weeks had a 3.5-point advantage over placebo in the Movement Disorders Society Unified Parkinson's Disease Rating Scale (MDS-UPDRS) [97]. In fact, this is the first time that a disease-modifying drug for the diabetes treatment had a relevant positive effect on PD progression [170]. Moreover, another study reported that the neuroprotection offered by exenatide persisted after 12 months of treatment in 20 patients with PD [98], thus providing positive evidence for the potential of GLP-1 agonists. Regarding GIP agonists (D-Ala2-GIP-glu-PAL), neuroprotection in MPTP-treated rats and cell cultures was confirmed through the reduction in dopaminergic neurons and an increase in the antiapoptotic protein $\mathrm{Bcl}-2$ ( $\beta$-cell lymphoma 2 ), which prevented apoptosis and reduced chronic brain inflammation [100, 102, 103]. Finally, DPP-4 inhibitors slow degradation of GLP-1 increasing the insulin secretion [171]. This drug has demonstrated antiparkinsonian effects [104-106] explained by the reduction in ROS expression, brain mitochondrial dysfunction in diabetic rats [104], and the suppression of neuroinflammatory and apoptotic cascades in models of PD induction in rats [105]. Moreover, a nationwide case-control study showed, for the first time, a decreased risk of future PD in patients using DPP-4 inhibitors [106]. However, the whole mechanism of action of DPP-4 against neurodegeneration in PD is not fully understood [172]. Hence, further studies on the neuroprotective potential of incretin mimetics for the treatment of PD should be conducted.

4.5.2. Antiparkinsonian Drugs. A relationship between T2DM and L-dopa therapy [71, 73] and dopaminergic agonists, especially bromocriptine [74, 76, 77, 80-83], has been detected. In trials with rodents, L-dopa therapy caused a decrease in insulin secretion in glucose tolerance tests due to the dopamine increase in pancreatic cells [173]. In addition, a partial loss of L-dopa efficacy in PD patients who developed T2DM [71] was observed probably because some 
pathophysiological mechanisms of T2DM can aggravate PD. Bromocriptine has an inhibitory effect on the production and release of prolactin, preventing disorders of carbohydrate and lipid metabolism due to the excessive amount of this hormone. In animals and patients with T2DM, there is an improvement in glucose intolerance [75, 78, 81, 174, 175], a reduction in the production of hepatic glucose, in serum lipid levels $[54,76,80,83]$ and in the risk of cardiovascular complications [77].

\section{Conclusion}

"In vitro" and animal studies suggest that T2DM causes neurological alterations that may be associated with PD, such as deregulation of the dopaminergic system, a decrease in the expression of peroxisome proliferator-activated receptorgamma coactivator- $1 \alpha(P G C-1 \alpha)$, an increase in the expression of phosphoprotein enriched in diabetes/phosphoprotein enriched in astrocytes 15 (PED/PEA-15), and neuroinflammation, as well as acceleration of the formation of alpha-synuclein amyloid fibrils. Epidemiological studies suggested that T2DM increases the risks of PD. In addition, clinical studies described that Parkinson's symptoms were notably worse after the onset of T2DM. Regarding treatment, the action of antidiabetic drugs, especially incretin mimetic agents, seems to confer a certain degree of neuroprotection to PD patients. In conclusion, the available evidence on the interaction between T2DM and PD justifies more robust clinical trials exploring this interaction especially the clinical management of patients with both conditions.

\section{Conflicts of Interest}

The authors declare that they have no conflicts of interest.

\section{References}

[1] O. Pinhas-Hamiel and P. Zeitler, "The global spread of type 2 diabetes mellitus in children and adolescents," The Journal of Pediatrics, vol. 146, no. 5, pp. 693-700, 2005.

[2] S. E. Kahn, M. E. Cooper, and S. Del Prato, "Pathophysiology and treatment of type 2 diabetes: perspectives on the past, present, and future," The Lancet, vol. 383, no. 9922, pp. 1068-1083, 2014.

[3] F. Zaccardi, D. R. Webb, T. Yates, and M. J. Davies, "Pathophysiology of type 1 and type 2 diabetes mellitus: a 90year perspective," Postgraduate Medical Journal, vol. 92, no. 1084, pp. 63-69, 2015.

[4] S. Bhattacharya, D. Dey, and S. S. Roy, "Molecular mechanism of insulin resistance," Journal of Biosciences, vol. 32, no. 2, pp. 405-413, 2007.

[5] I. Obasse, M. Taylor, N. J. Fullwood, and D. Allsop, "Development of proteolytically stable $\mathrm{N}$-methylated peptide inhibitors of aggregation of the amylin peptide implicated in type 2 diabetes," Interface Focus, vol. 7, no. 6, Article ID 20160127, 2017.

[6] M. Lima, A. Targa, A. Noseda et al., "Does Parkinson's disease and type-2 diabetes mellitus present common pathophysiological mechanisms and treatments?," CNS \& Neurological Disorders-Drug Targets, vol. 13, no. 3, pp. 418-428, 2014.
[7] T. R. Mhyre, J. T. Boyd, R. W. Hamill, and K. A. MaguireZeiss, "Parkinson's disease," Protein Aggregation and Fibrillogenesis in Cerebral and Systemic Amyloid Disease, vol. 65, pp. 389-455, 2012.

[8] H. H. Fernandez, "2015 Update on Parkinson disease," Cleveland Clinic Journal of Medicine, vol. 82, no. 9, pp. 563-568, 2015.

[9] B. Thomas and M. F. Beal, "Parkinson's disease," Human Molecular Genetics, vol. 16, pp. 183-194, 2007.

[10] L. Stefanis, “-Synuclein in Parkinson's disease,” Cold Spring Harbor Perspectives in Medicine, vol. 2, no. 2, Article ID a009399, 2011.

[11] F. Emamzadeh, "Alpha-synuclein structure, functions, and interactions," Journal of Research in Medical Sciences, vol. 21, no. 1, p. 29, 2016.

[12] G. Rodriguez-Araujo, H. Nakagami, Y. Takami et al., "Low alpha-synuclein levels in the blood are associated with insulin resistance," Science Reports, vol. 5, no. 1, p. 12081, 2015.

[13] J. Shendure and G. M. Church, "Computational discovery of sense-antisense transcription in the human and mouse genomes," Genome Biology, vol. 3, no. 9, Article ID research0044.1, 2002.

[14] L. Xu and J. Pu, "Alpha-synuclein in Parkinson's disease: from pathogenetic dysfunction to potential clinical application," Parkinson's Disease, vol. 2016, pp. 1-10, 2016.

[15] G. Tamgüney and A. D. Korczyn, "A critical review of the prion hypothesis of human synucleinopathies," Cell and Tissue Research, vol. 373, no. 1, pp. 213-220, 2018.

[16] A. Oueslati, M. Ximerakis, and K. Vekrellis, "Protein transmission, seeding and degradation: key steps for $\alpha$-synuclein prion-like propagation," Experimental Neurobiology, vol. 23, no. 4, p. 324, 2014.

[17] I. Horvath and P. Wittung-Stafshede, "Cross-talk between amyloidogenic proteins in type-2 diabetes and Parkinson's disease," Proceedings of the National Academy of Sciences, vol. 113, no. 44, pp. 12473-12477, 2016.

[18] I. Aviles-Olmos, P. Limousin, A. Lees, and T. Foltynie, "Parkinson's disease, insulin resistance and novel agents of neuroprotection," Brain, vol. 136, no. 2, pp. 374-384, 2012.

[19] G. Hu, P. Jousilahti, S. Bidel, R. Antikainen, and J. Tuomilehto, "Type 2 diabetes and the risk of Parkinson's disease," Diabetes Care, vol. 30, no. 4, pp. 842-847, 2007.

[20] E. De Pablo-Fernandez, R. Goldacre, J. Pakpoor, A. J. Noyce, and T. T. Warner, "Association between diabetes and subsequent Parkinson disease," Neurology, vol. 91, no. 2, pp. e139-e142, 2018.

[21] L. Lu, D.-l. Fu, H.-q. Li, A.-j. Liu, J.-h. Li, and G.-q. Zheng, "Diabetes and risk of Parkinson's disease: an updated metaanalysis of case-control studies," PLoS One, vol. 9, no. 1, Article ID e85781, 2014.

[22] R. Savica, B. R. Grossardt, J. E. Ahlskog, and W. A. Rocca, "Metabolic markers or conditions preceding Parkinson's disease: a case-control study," Movement Disorders, vol. 27, no. 8, pp. 974-979, 2012.

[23] M. H. V. Woert and P. S. Mueller, "Glucose, insulin, and free fatty acid metabolism in Parkinson's disease treated with levodopa," Clinical Pharmacology \& Therapeutics, vol. 12, no. 2, pp. 360-367, 1971.

[24] C. Shivaprasad and S. Kalra, "Bromocriptine in type 2 diabetes mellitus," Indian Journal of Endocrinology and Metabolism, vol. 15, no. 5, pp. S17-S24, 2011.

[25] N. Katila, S. Bhurtel, S. Shadfar et al., "Metformin lowers $\alpha$-synuclein phosphorylation and upregulates neurotrophic 
factor in the MPTP mouse model of Parkinson's disease," Neuropharmacology, vol. 125, pp. 396-407, 2017.

[26] T. Obata and M. Nakashima, "Opening of ATP-sensitive K + (K ATP) channels enhance hydroxyl radical generation induced by MPP + in rat striatum," Journal of the Neurological Sciences, vol. 366, pp. 180-183, 2016.

[27] F. Bassil, M.-H. Canron, A. Vital et al., "Insulin resistance and exendin-4 treatment for multiple system atrophy," Brain, vol. 140, no. 5, pp. 1420-1436, 2017.

[28] M. Pinto, N. Nissanka, S. Peralta, R. Brambilla, F. Diaz, and C. Moraes, "Pioglitazone ameliorates the phenotype of a novel Parkinson's disease mouse model by reducing neuroinflammation," Molecular Neurodegeneration, vol. 11, no. 1, p. 25, 2016.

[29] C. Perier, K. Tieu, C. Guegan et al., "Complex I deficiency primes bax-dependent neuronal apoptosis through mitochondrial oxidative damage," Proceedings of the National Academy of Sciences, vol. 102, no. 52, pp. 19126-19131, 2005.

[30] E. Deas, K. Piipari, A. Machhada et al., "PINK1 deficiency in $\beta$-cells increases basal insulin secretion and improves glucose tolerance in mice," Open Biology, vol. 4, no. 5, p. 140051, 2014.

[31] L. Wang, Y.-Q. Zhai, L.-L. Xu et al., "Metabolic inflammation exacerbates dopaminergic neuronal degeneration in response to acute MPTP challenge in type 2 diabetes mice," Experimental Neurology, vol. 251, pp. 22-29, 2014.

[32] J. K. Morris, G. L. Bomhoff, B. K. Gorres et al., "Insulin resistance impairs nigrostriatal dopamine function," $E x$ perimental Neurology, vol. 231, no. 1, pp. 171-180, 2011.

[33] G. D. Baura, D. M. Foster, D. Porte et al., "Saturable transport of insulin from plasma into the central nervous system of dogs in vivo. A mechanism for regulated insulin delivery to the brain," Journal of Clinical Investigation, vol. 92, no. 4, pp. 1824-1830, 1993.

[34] D. Figlewicz, M. D. Brot, A. L. McCall, and P. Szot, "Diabetes causes differential changes in CNS noradrenergic and dopaminergic neurons in the rat: a molecular study," Brain Research, vol. 736, no. 1-2, pp. 54-60, 1996.

[35] J. Renaud, V. Bassareo, J. Beaulieu et al., "Dopaminergic neurodegeneration in a rat model of long-term hyperglycemia: preferential degeneration of the nigrostriatal motor pathway," Neurobiology of Aging, vol. 69, pp. 117-128, 2018.

[36] M. E. Patti, A. J. Butte, S. Crunkhorn et al., "Coordinated reduction of genes of oxidative metabolism in humans with insulin resistance and diabetes: Potential role ofPGClandNRF1," Proceedings of the National Academy of Sciences, vol. 100, no. 14, pp. 8466-8471, 2003.

[37] J.-H. Shin, H. S. Ko, H. Kang et al., "PARIS (ZNF746) Repression of $P G C-1 \alpha$ contributes to neurodegeneration in Parkinson's disease," Cell, vol. 144, no. 5, pp. 689-702, 2011.

[38] C. Mounier and B. I. Posner, "Transcriptional regulation by insulin: from the receptor to the gene," Canadian Journal of Physiology and Pharmacology, vol. 84, no. 7, pp. 713-724, 2006.

[39] R. Khang, C. Park, and J.-H. Shin, "Dysregulation of parkin in the substantia nigra of $\mathrm{db} / \mathrm{db}$ and high-fat diet mice," Neuroscience, vol. 294, pp. 182-192, 2015.

[40] G. Perruolo, D. Viggiano, F. Fiory et al., "Parkinson-like phenotype in insulin-resistant PED/PEA-15 transgenic mice," Science Reports, vol. 6, no. 1, Article ID 29967, 2016.

[41] D.-W. Song, N. Xin, B.-J. Xie et al., "Formation of a salsolinol-like compound, the neurotoxin, 1-acetyl-6,7-dihydroxy-1,2,3,4-tetrahydroisoquinoline, in a cellular model of hyperglycemia and a rat model of diabetes," International
Journal of Molecular Medicine, vol. 33, no. 3, pp. 736-742, 2013.

[42] B. Xie, F. Lin, K. Ullah et al., "A newly discovered neurotoxin ADTIQ associated with hyperglycemia and Parkinson's disease," Biochemical and Biophysical Research Communications, vol. 459, no. 3, pp. 361-366, 2015.

[43] E. De Pablo-Fernandez, F. Sierra-Hidalgo, J. Benito-León, and F. Bermejo-Pareja, "Association between Parkinson's disease and diabetes: data from NEDICES study," Acta Neurologica Scandinavica, vol. 136, no. 6, pp. 732-736, 2017.

[44] Y.-W. Yang, T.-F. Hsieh, C.-I. Li et al., "Increased risk of Parkinson disease with diabetes mellitus in a populationbased study," Medicine, vol. 96, no. 3, p. e5921, 2017.

[45] X. Yue, H. Li, H. Yan, P. Zhang, L. Chang, and T. Li, "Risk of Parkinson disease in diabetes mellitus," Medicine, vol. 95, no. 18, p. e3549, 2016.

[46] Y. Sun, Y.-H. Chang, H.-F. Chen, Y.-H. Su, H.-F. Su, and C.-Y. Li, "Risk of Parkinson disease onset in patients with diabetes: a 9-year population-based cohort study with age and sex stratifications," Diabetes Care, vol. 35, no. 5, pp. 1047-1049, 2012.

[47] M. L. Wahlqvist, M.-S. Lee, C.-C. Hsu, S.-Y. Chuang, J.-T. Lee, and H.-N. Tsai, "Metformin-inclusive sulfonylurea therapy reduces the risk of Parkinson's disease occurring with type 2 diabetes in a Taiwanese population cohort," Parkinsonism \& Related Disorders, vol. 18, no. 6, pp. 753758, 2012.

[48] E. Schernhammer, J. Hansen, K. Rugbjerg, L. Wermuth, and B. Ritz, "Diabetes and the risk of developing Parkinson's disease in Denmark," Diabetes Care, vol. 34, no. 5, pp. 1102-1108, 2011.

[49] Q. Xu, Y. Park, X. Huang et al., "Diabetes and risk of Parkinson's disease," Diabetes Care, vol. 34, no. 4, pp. 910-915, 2011.

[50] Y. Miyake, K. Tanaka, W. Fukushima et al., "Case-control study of risk of Parkinson's disease in relation to hypertension, hypercholesterolemia, and diabetes in Japan," Journal of the Neurological Sciences, vol. 293, no. 1-2, pp. 82-86, 2010.

[51] M. D’Amelio, P. Ragonese, G. Callari et al., "Diabetes preceding Parkinson's disease onset: a case-control study," Parkinsonism \& Related Disorders, vol. 15, no. 9, pp. 660664, 2009.

[52] C. L. Leibson, D. M. Maraganore, J. H. Bower, J. E. Ransom, P. C. O'Brien, and W. A. Rocca, "Comorbid conditions associated with Parkinson's disease: a population-based study," Movement Disorders, vol. 21, no. 4, pp. 446-455, 2006.

[53] K. M. Powers, T. Smith-Weller, G. M. Franklin, W. T. Longstreth, P. D. Swanson, and H. Checkoway, "Diabetes, smoking, and other medical conditions in relation to Parkinson's disease risk," Parkinsonism \& Related Disorders, vol. 12, no. 3, pp. 185-189, 2006.

[54] Y. O. Herishanu, M. Medvedovski, J. R. Goldsmith, and E. Kordysh, "A case-control study of Parkinson's disease in urban population of Southern Israel," Canadian Journal of Neurological Sciences / Journal Canadien des Sciences Neurologiques, vol. 28, no. 2, pp. 144-147, 2001.

[55] N. Palacios, X. Gao, M. L. McCullough et al., "Obesity, diabetes, and risk of Parkinson's disease," Movement Disorders, vol. 26, no. 12, pp. 2253-2259, 2011.

[56] J. A. Driver, A. Smith, J. E. Buring, J. M. Gaziano, T. Kurth, and G. Logroscino, "Prospective cohort study of type 2 
diabetes and the risk of Parkinson's disease," Diabetes Care, vol. 31, no. 10, pp. 2003-2005, 2008.

[57] K. C. Simon, H. Chen, M. Schwarzschild, and A. Ascherio, "Hypertension, hypercholesterolemia, diabetes, and risk of Parkinson disease," Neurology, vol. 69, no. 17, pp. 1688-1695, 2007.

[58] C. Becker, G. P. Brobert, S. Johansson, S. S. Jick, and C. R. Meier, "Diabetes in patients with idiopathic Parkinson's disease," Diabetes Care, vol. 31, no. 9, pp. 1808-1812, 2008.

[59] G. Scigliano, M. Musicco, P. Soliveri, I. Piccolo, G. Ronchetti, and F. Girotti, "Reduced risk factors for vascular disorders in Parkinson disease patients," Stroke, vol. 37, no. 5, pp. 1184-1188, 2006.

[60] J. C. Pressley, E. D. Louis, M.-X. Tang et al., "The impact of comorbid disease and injuries on resource use and expenditures in Parkinsonism," Neurology, vol. 60, no. 1, pp. 8793, 2003.

[61] S. J. Chung, M.-J. Kim, J. Kim et al., "Association of type 2 diabetes GWAS loci and the risk of Parkinson's and Alzheimer's diseases," Parkinsonism \& Related Disorders, vol. 21, no. 12, pp. 1435-1440, 2015.

[62] J. A. Santiago, C. R. Scherzer, and J. A. Potashkin, "Network Analysis Identifies SOD2 mRNA as a Potential Biomarker for Parkinson's disease," PLoS One, vol. 9, no. 10, Article ID e109042, 2014.

[63] J. A. Santiago and J. A. Potashkin, "Integrative network analysis unveils convergent molecular pathways in Parkinson's disease and diabetes," PLoS One, vol. 8, no. 12, Article ID e83940, 2013.

[64] S. Takasaki, "Mitochondrial haplogroups associated with Japanese centenarians, Alzheimer's patients, Parkinson's patients, type 2 diabetic patients and healthy non-obese young males," Journal of Genetics and Genomics, vol. 36, no. 7, pp. 425-434, 2009.

[65] M. Ong, H. Foo, R. J. Chander et al., "Influence of diabetes mellitus on longitudinal atrophy and cognition in Parkinson's disease," Journal of the Neurological Sciences, vol. 377, pp. 122-126, 2017.

[66] M. Petrou, C. Davatzikos, M. Hsieh et al., "Diabetes, gray matter loss, and cognition in the setting of Parkinson disease," Academic Radiology, vol. 23, no. 5, pp. 577-581, 2016.

[67] N. I. Bohnen, V. Kotagal, M. L. T. M. Müller et al., "Diabetes mellitus is independently associated with more severe cognitive impairment in Parkinson disease," Parkinsonism \& Related Disorders, vol. 20, no. 12, pp. 1394-1398, 2014.

[68] N. Mohamed Ibrahim, R. Ramli, S. Koya Kutty, and S. A. Shah, "Earlier onset of motor complications in Parkinson's patients with comorbid diabetes mellitus," Movement Disorders, vol. 33, no. 12, pp. 1967-1968, 2018.

[69] G. Pagano, S. Polychronis, H. Wilson et al., "Diabetes mellitus and Parkinson disease," Neurology, vol. 90, no. 19, pp. e1654-e1662, 2018.

[70] V. Kotagal, R. L. Albin, M. L. T. M. Müller, R. A. Koeppe, K. A. Frey, and N. I. Bohnen, "Diabetes is associated with postural instability and gait difficulty in Parkinson disease," Parkinsonism \& Related Disorders, vol. 19, no. 5, pp. 522526, 2013.

[71] E. Cereda, M. Barichella, E. Cassani, R. Caccialanza, and G. Pezzoli, "Clinical features of Parkinson disease when onset of diabetes came first: a case-control study," Neurology, vol. 78, no. 19, pp. 1507-1511, 2012.

[72] N. Scheuing, F. Best, A. Dapp et al., "DPV initiative and the German BMBF competence network diabetes mellitus multicentre analysis of 178,992 type 2 diabetes patients revealed better metabolic control despite higher rates of hypertension, stroke, dementia and repeated inpatient care in patients with comorbid Parkinson's disease," Parkinsonism \& Related Disorders, vol. 19, no. 7, pp. 687-692, 2013.

[73] G. Rosati, M. Maioli, I. Aiello, A. Farris, and V. Agnetti, "Effects of long-term L-dopa therapy on carbohydrate metabolism in patients with Parkinson's disease," European Neurology, vol. 14, no. 3, pp. 229-239, 1976.

[74] B. Chamarthi and A. H. Cincotta, "Effect of bromocriptineQR therapy on glycemic control in subjects with type 2 diabetes mellitus whose dysglycemia is inadequately controlled on insulin," Postgraduate Medicine, vol. 129, no. 4, pp. 446-455, 2017.

[75] E. D. Roe, B. Chamarthi, and P. Raskin, "Impact of bromocriptine-QR Therapy on glycemic control and daily insulin requirement in type 2 diabetes mellitus subjects whose dysglycemia is poorly controlled on high-dose insulin: a pilot study," Journal of Diabetes Research, vol. 2015, pp. 1-7, 2015.

[76] A. Ghosh, N. Sengupta, P. Sahana, D. Giri, P. Sengupta, and N. Das, "Efficacy and safety of add on therapy of bromocriptine with metformin in Indian patients with type 2 diabetes mellitus: a randomized open labeled phase IV clinical trial," Indian Journal of Pharmacology, vol. 46, no. 1, p. 24, 2014.

[77] J. M. Gaziano, A. H. Cincotta, A. Vinik, L. Blonde, N. Bohannon, and R. Scranton, "Effect of bromocriptine-QR (a quick-release formulation of bromocriptine mesylate) on major adverse cardiovascular events in type 2 diabetes subjects," Journal of the American Heart Association, vol. 1, no. 5, Article ID e002279, 2012.

[78] A. Vinik, A. Cincotta, R. Scranton, N. Bohannon, M. Ezrokhi, and J. Gaziano, "Effect of bromocriptine-QR on glycemic control in subjects with uncontrolled hyperglycemia on one or two oral anti-diabetes agents," Endocrine Practice, vol. 18, no. 6, pp. 931-943, 2012.

[79] H. Pijl, S. Ohashi, M. Matsuda et al., "Bromocriptine: a novel approach to the treatment of type 2 diabetes," Diabetes Care, vol. 23, no. 8, pp. 1154-1161, 2000.

[80] M. Ezrokhi, S. Luo, Y. Trubitsyna, and A. H. Cincotta, "Neuroendocrine and metabolic components of dopamine agonist amelioration of metabolic syndrome in SHR rats," Diabetology \& Metabolic Syndrome, vol. 6, no. 1, p. 104, 2014.

[81] S. Luo, J. Luo, and A. H. Cincotta, "Association of the antidiabetic effects of bromocriptine with a shift in the daily rhythm of monoamine metabolism within the suprachiasmatic nuclei of the Syrian hamster," Chronobiology International, vol. 17, no. 2, pp. 155-172, 2000.

[82] S. Luo, A. H. Meier, and A. H. Cincotta, "Bromocriptine reduces obesity, glucose intolerance and extracellular monoamine metabolite levels in the ventromedial hypothalamus of Syrian hamsters," Neuroendocrinology, vol. 68, no. 1, pp. 1-10, 1998.

[83] A. H. Cincotta and A. H. Meier, "Bromocriptine inhibits in vivo free fatty acid oxidation and hepatic glucose output in seasonally obese hamsters (Mesocricetus auratus)," Metabolism, vol. 44, no. 10, pp. 1349-1355, 1995.

[84] Y.-K. Ryu, H.-Y. Park, J. Go et al., "Metformin inhibits the development of 1-DOPA-induced dyskinesia in a murine model of Parkinson's disease," Molecular Neurobiology, vol. 55, no. 7, pp. 5715-5726, 2018.

[85] A. A. K. Ismaiel, A. M. Espinosa-Oliva, M. Santiago et al., "Metformin, besides exhibiting strong in vivo anti-inflammatory properties, increases mptp-induced damage to 
the nigrostriatal dopaminergic system," Toxicology and Applied Pharmacology, vol. 298, pp. 19-30, 2016.

[86] S. P. Patil, P. D. Jain, P. J. Ghumatkar, R. Tambe, and S. Sathaye, "Neuroprotective effect of metformin in MPTPinduced Parkinson's disease in mice," Neuroscience, vol. 277, pp. 747-754, 2014.

[87] J.-S. Choi, C. Park, and J.-W. Jeong, "AMP-activated protein kinase is activated in Parkinson's disease models mediated by 1-methyl-4-phenyl-1,2,3,6-tetrahydropyridine," Biochemical and Biophysical Research Communications, vol. 391, no. 1, pp. 147-151, 2010.

[88] Y.-C. Kuan, K.-W. Huang, C.-L. Lin, C.-J. Hu, and C.-H. Kao, "Effects of metformin exposure on neurodegenerative diseases in elderly patients with type 2 diabetes mellitus," Progress in Neuro-Psychopharmacology and Biological Psychiatry, vol. 79, pp. 77-83, 2017.

[89] J. C. Fitzgerald, A. Zimprich, D. A. Carvajal Berrio et al., "Metformin reverses TRAP1 mutation-associated alterations in mitochondrial function in Parkinson's disease," Brain, vol. 140, no. 9, pp. 2444-2459, 2017.

[90] L. Zhang, L. Zhang, L. Li, and C. Hölscher, "Semaglutide is neuroprotective and reduces $\alpha$-synuclein levels in the chronic MPTP mouse model of Parkinson's disease," Journal of Parkinson's Disease, vol. 9, no. 1, pp. 157-171, 2019.

[91] L. Cao, D. Li, P. Feng et al., "A novel dual GLP-1 and GIP incretin receptor agonist is neuroprotective in a mouse model of Parkinson's disease by reducing chronic inflammation in the brain," NeuroReport, vol. 27, no. 6, pp. 384-391, 2016.

[92] H. H. Hansen, K. Fabricius, P. Barkholt et al., "Characterization of liraglutide, a glucagon-like peptide-1 (GLP-1) receptor agonist, in rat partial and full nigral 6-hydroxydopamine lesion models of Parkinson's disease," Brain Research, vol. 1646, pp. 354-365, 2016.

[93] S. Kim, M. Moon, and S. Park, "Exendin-4 protects dopaminergic neurons by inhibition of microglial activation and matrix metalloproteinase- 3 expression in an animal model of Parkinson's disease," Journal of Endocrinology, vol. 202, no. 3, pp. 431-439, 2009.

[94] Y. Li, T. Perry, M. S. Kindy, B. K. Harvey et al., "GLP-1 receptor stimulation preserves primary cortical and dopaminergic neurons in cellular and rodent models of stroke and Parkinsonism," Proceedings of the National Academy of Sciences, vol. 106, no. 4, pp. 1285-1290, 2009.

[95] G. Bertilsson, C. Patrone, O. Zachrisson et al., "Peptide hormone exendin- 4 stimulates subventricular zone neurogenesis in the adult rodent brain and induces recovery in an animal model of Parkinson's disease," Journal of Neuroscience Research, vol. 86, no. 2, pp. 326-338, 2008.

[96] A. Harkavyi, A. Abuirmeileh, R. Lever, A. E. Kingsbury, C. S. Biggs, and P. S. Whitton, "Glucagon-like peptide 1 receptor stimulation by exendin-4 reverses key deficits in distinct rodent models of Parkinson's disease," Journal of Neuroinflammation, vol. 5, no. 1, p. 19, 2008.

[97] D. Athauda, K. Maclagan, S. S. Skene et al., "Exenatide once weekly versus placebo in Parkinson's disease: a randomised, double-blind, placebo-controlled trial," The Lancet, vol. 390, no. 10103, pp. 1664-1675, 2017.

[98] I. Aviles-Olmos, J. Dickson, Z. Kefalopoulou et al., "Motor and cognitive advantages persist 12 months after exenatide exposure in Parkinson's disease," Journal of Parkinson's Disease, vol. 4, no. 3, pp. 337-344, 2015.

[99] I. Aviles-Olmos, J. Dickson, Z. Kefalopoulou et al., "Exenatide and the treatment of patients with Parkinson's disease," Journal of Clinical Investigation, vol. 123, no. 6, pp. 2730-2736, 2013.

[100] J. Jalewa, M. K. Sharma, and C. Hölscher, "Novel incretin analogues improve autophagy and protect from mitochondrial stress induced by rotenone in SH-SY5Y cells," Journal of Neurochemistry, vol. 139, no. 1, pp. 55-67, 2016.

[101] T. Perry, D. K. Lahiri, D. Chen et al., "A novel neurotrophic property of glucagon-like peptide 1: a promoter of nerve growth factor-mediated differentiation in PC12 cells," Journal of Pharmacology and Experimental Therapeutics, vol. 300, no. 3, pp. 958-966, 2002.

[102] P. Feng, X. Zhang, D. Li et al., "Two novel dual GLP-1/GIP receptor agonists are neuroprotective in the MPTP mouse model of Parkinson's disease," Neuropharmacology, vol. 133, pp. 385-394, 2018.

[103] Y. Li, W. Liu, L. Li, and C. Hölscher, "D-Ala2-GIP-glu-PAL is neuroprotective in a chronic Parkinson's disease mouse model and increases BNDF expression while reducing neuroinflammation and lipid peroxidation," European Journal of Pharmacology, vol. 797, pp. 162-172, 2017.

[104] R. M. Abdelsalam and M. M. Safar, "Neuroprotective effects of vildagliptin in rat rotenone Parkinson's disease model: role of RAGE-NFkB and Nrf2-antioxidant signaling pathways," Journal of Neurochemistry, vol. 133, no. 5, pp. 700707, 2015.

[105] N. Pipatpiboon, H. Pintana, W. Pratchayasakul, N. Chattipakorn, and S. C. Chattipakorn, "DPP4-inhibitor improves neuronal insulin receptor function, brain mitochondrial function and cognitive function in rats with insulin resistance induced by high-fat diet consumption," European Journal of Neuroscience, vol. 37, no. 5, pp. 839-849, 2012.

[106] P. Svenningsson, K. Wirdefeldt, L. Yin et al., "Reduced incidence of Parkinson's disease after dipeptidyl peptidase-4 inhibitors-A nationwide case-control study," Movement Disorders, vol. 31, no. 9, pp. 1422-1423, 2016.

[107] J. Kou, D. C. Klorig, and J. R. Bloomquist, "Potentiating effect of the ATP-sensitive potassium channel blocker glibenclamide on complex I inhibitor neurotoxicity in vitro and in vivo," NeuroToxicology, vol. 27, no. 5, pp. 826-834, 2006.

[108] K.-K. Tai and D. D. Truong, "Activation of adenosine triphosphate-sensitive potassium channels confers protection against rotenone-induced cell death: Therapeutic implications for Parkinson's disease," Journal of Neuroscience Research, vol. 69, no. 4, pp. 559-566, 2002.

[109] A. A. Martinez, M. G. Morgese, A. Pisanu et al., "Activation of PPAR gamma receptors reduces levodopa-induced dyskinesias in 6-OHDA-lesioned rats," Neurobiology of Disease, vol. 74, pp. 295-304, 2015.

[110] Z. Ren, N. Yang, C. Ji et al., "Neuroprotective effects of 5-(4hydroxy-3-dimethoxybenzylidene)-thiazolidinone in MPTP induced Parkinsonism model in mice," Neuropharmacology, vol. 93, pp. 209-218, 2015.

[111] J. K. Barbiero, R. M. Santiago, D. S. Persike et al., "Neuroprotective effects of peroxisome proliferator-activated receptor alpha and gamma agonists in model of parkinsonism induced by intranigral 1-methyl-4-phenyl-1,2,3,6tetrahyropyridine," Behavioural Brain Research, vol. 274, pp. 390-399, 2014.

[112] A. Pisanu, D. Lecca, G. Mulas et al., "Dynamic changes in pro- and anti-inflammatory cytokines in microglia after PPAR- $\gamma$ agonist neuroprotective treatment in the MPTPp mouse model of progressive Parkinson's disease," Neurobiology of Disease, vol. 71, pp. 280-291, 2014. 
[113] L. P. Quinn, B. Crook, M. E. Hows et al., “The PPAR $\gamma$ agonist pioglitazone is effective in the MPTP mouse model of Parkinson's disease through inhibition of monoamine oxidase B," British Journal of Pharmacology, vol. 154, no. 1, pp. 226-233, 2008.

[114] R. L. Hunter, N. Dragicevic, K. Seifert et al., "Inflammation induces mitochondrial dysfunction and dopaminergic neurodegeneration in the nigrostriatal system," Journal of Neurochemistry, vol. 100, no. 5, pp. 1375-1386, 2007.

[115] T. Dehmer, M. T. Heneka, M. Sastre, J. Dichgans, and J. B. Schulz, "Protection by pioglitazone in the MPTP model of Parkinson's disease correlates with $\mathrm{I} \kappa \mathrm{B} \alpha$ induction and block of NFKB and iNOS activation," Journal of Neurochemistry, vol. 88, no. 2, pp. 494-501, 2003.

[116] T. Breidert, J. Callebert, M. T. Heneka, G. Landreth, J. M. Launay, and E. C. Hirsch, "Protective action of the peroxisome proliferator-activated receptor- $\gamma$ agonist pioglitazone in a mouse model of Parkinson's disease," Journal of Neurochemistry, vol. 82, no. 3, pp. 615-624, 2002.

[117] B. Brakedal, I. Flønes, S. F. Reiter et al., "Glitazone use associated with reduced risk of Parkinson's disease," Movement Disorders, vol. 32, no. 11, pp. 1594-1599, 2017.

[118] R. Brauer, K. Bhaskaran, N. Chaturvedi, D. T. Dexter, L. Smeeth, and I. Douglas, "Glitazone treatment and incidence of Parkinson's disease among people with diabetes: a retrospective cohort study," PLOS Medicine, vol. 12, no. 7, Article ID e1001854, 2015.

[119] NINDS Exploratory Trials in Parkinson Disease FS-ZONE, Investigators, "Pioglitazone in early Parkinson's disease: a phase 2, multicentre, double-blind, randomised trial," The Lancet Neurology, vol. 14, no. 8, pp. 795-803, 2015.

[120] D. K. Simon, T. Simuni, J. Elm et al., "Peripheral biomarkers of Parkinson's disease progression and pioglitazone effects," Journal of Parkinson's Disease, vol. 5, no. 4, pp. 731-736, 2015.

[121] T. W. Jung, J. Y. Lee, W. S. Shim et al., "Rosiglitazone protects human neuroblastoma SH-SY5Y cells against MPP+ induced cytotoxicity via inhibition of mitochondrial dysfunction and ROS production," Journal of the Neurological Sciences, vol. 253, no. 1-2, pp. 53-60, 2007.

[122] B. Xing, M. Liu, and G. Bing, "Neuroprotection with pioglitazone against LPS insult on dopaminergic neurons may be associated with its inhibition of NF- $\mathrm{\kappa B}$ and JNK activation and suppression of COX-2 activity," Journal of Neuroimmunology, vol. 192, no. 1-2, pp. 89-98, 2007.

[123] E. Cereda, M. Barichella, C. Pedrolli et al., "Diabetes and risk of Parkinson's disease: a systematic review and meta-analysis," Diabetes Care, vol. 34, no. 12, pp. 2614-2623, 2011.

[124] O.-B. Tysnes and A. Storstein, "Epidemiology of Parkinson's disease," Journal of Neural Transmission, vol. 124, no. 8, pp. 901-905, 2017.

[125] J. M. Fernandez-Real, A. Lopez-Bermejo, and W. Ricart, "Cross-talk between iron metabolism and diabetes," Diabetes, vol. 51, no. 8, pp. 2348-2354, 2002.

[126] S. L. Rhodes and B. Ritz, "Genetics of iron regulation and the possible role of iron in Parkinson's disease," Neurobiology of Disease, vol. 32, no. 2, pp. 183-195, 2008.

[127] C. R. Sirtori, P. Bolme, and D. L. Azarnoff, "Metabolic responses to acute and chronic L-dopa administration in patients with Parkinsonism," New England Journal of Medicine, vol. 287, no. 15, pp. 729-733, 1972.

[128] R. Sandyk, "The relationship between diabetes mellitus and Parkinson's disease," International Journal of Neuroscience, vol. 69, no. 1-4, pp. 125-130, 1993.
[129] E. R. Dorsey, R. Constantinescu, J. P. Thompson et al., "Projected number of people with Parkinson disease in the most populous nations, 2005 through 2030," Neurology, vol. 68 , no. 5, pp. 384-386, 2006.

[130] J. Liu, Y. Wu, X. Huang et al., "Ageing and type 2 diabetes in an elderly Chinese population: the role of insulin resistance and beta cell dysfunction," European Review for Medical and Pharmacological Sciences, vol. 18, pp. 1790-1797, 2014.

[131] M. A. Hernán, B. Takkouche, F. Caamaño-Isorna, and J. J. Gestal-Otero, "A meta-analysis of coffee drinking, cigarette smoking, and the risk of Parkinson's disease," Annals of Neurology, vol. 52, no. 3, pp. 276-284, 2002.

[132] J. A. Santiago and J. A. Potashkin, "System-based approaches to decode the molecular links in Parkinson's disease and diabetes," Neurobiology of Disease, vol. 72, pp. 84-91, 2014.

[133] Y. Yoon, C. A. Galloway, B. S. Jhun, and T. Yu, "Mitochondrial dynamics in diabetes," Antioxidants \& Redox Signaling, vol. 14, no. 3, pp. 439-457, 2011.

[134] D. S. Karolina, A. Armugam, S. Tavintharan et al., "MicroRNA 144 impairs insulin signaling by inhibiting the expression of insulin receptor substrate 1 in type 2 diabetes mellitus," PLoS One, vol. 6, no. 8, Article ID e22839, 2011.

[135] J. A. Potashkin, J. A. Santiago, B. M. Ravina, A. Watts, and A. A. Leontovich, "Biosignatures for Parkinson's disease and Atypical Parkinsonian disorders patients," PLoS One, vol. 7, no. 8, Article ID e43595, 2012.

[136] J. A. Kulas, K. L. Puig, and C. K. Combs, "Amyloid precursor protein in pancreatic islets," Journal of Endocrinology, vol. 235, no. 1, pp. 49-67, 2017.

[137] B. Van Harten, F.-E. de Leeuw, H. C. Weinstein, P. Scheltens, and G. J. Biessels, "Brain imaging in patients with diabetes: a systematic review," Diabetes Care, vol. 29, no. 11, pp. 2539-2548, 2006.

[138] P. T. Nelson, C. D. Smith, E. A. Abner et al., "Human cerebral neuropathology of Type 2 diabetes mellitus," Biochimica et Biophysica Acta (BBA)-Molecular Basis of Disease, vol. 1792, no. 5, pp. 454-469, 2009.

[139] C. Becker, S. S. Jick, and C. R. Meier, "Risk of stroke in patients with idiopathic Parkinson disease," Parkinsonism \& Related Disorders, vol. 16, no. 1, pp. 31-35, 2010.

[140] X. Guo, W. Song, K. Chen et al., "The serum lipid profile of Parkinson's disease patients: a study from China," International Journal of Neuroscience, vol. 125, no. 11, pp. 838-844, 2015.

[141] M. G. Tansey, “Neuroinflammation in Parkinson's disease: is there sufficient evidence for mechanism-based interventional therapy?," Frontiers in Bioscience, vol. 13, no. 13, pp. 709-717, 2008.

[142] P. A. Ballard, J. W. Tetrud, and J. W. Langston, "Permanent human parkinsonism due to 1-methy 1-4-phenyl-1,2,3,6tetrahydropyridine (MPTP): seven cases," Neurology, vol. 35, no. 7, p. 949, 1985.

[143] J. Langston, P. Ballard, J. Tetrud, and I. Irwin, "Chronic Parkinsonism in humans due to a product of meperidineanalog synthesis," Science, vol. 219, no. 4587, pp. 979-980, 1983.

[144] M. Gerlach, P. Riederer, H. Przuntek, and M. B. H. Youdim, "MPTP mechanisms of neurotoxicity and their implications for Parkinson's disease," European Journal of Pharmacology: Molecular Pharmacology, vol. 208, no. 4, pp. 273-286, 1991.

[145] J. Szendroedi, E. Phielix, and M. Roden, "The role of mitochondria in insulin resistance and type 2 diabetes mellitus," Nature Reviews Endocrinology, vol. 8, no. 2, pp. 92-103, 2011. 
[146] M. H. Polymeropoulos, C. Lavedan, E. Leroy et al., "Mutation in the -synuclein gene identified in families with Parkinson's disease," Science, vol. 276, no. 5321, pp. 2045-2047, 1997.

[147] H. I. Lebovitz, "Insulin resistance: definition and consequences," Experimental and Clinical Endocrinology \& Diabetes, vol. 109, no. 2, pp. 135-148, 2001.

[148] D. Jain, R. Jain, D. Eberhard et al., "Age- and diet-dependent requirement of DJ-1 for glucose homeostasis in mice with implications for human type 2 diabetes," Journal of Molecular Cell Biology, vol. 4, no. 4, pp. 221-230, 2012.

[149] J. Lu, E. Randell, Y. Han, K. Adeli, J. Krahn, and Q. H. Meng, "Increased plasma methylglyoxal level, inflammation, and vascular endothelial dysfunction in diabetic nephropathy," Clinical Biochemistry, vol. 44, no. 4, pp. 307-311, 2011.

[150] Y. Deng, Y. Zhang, Y. Li et al., "Occurrence and distribution of salsolinol-like compound, 1-acetyl-6,7-dihydroxy-1,2,3,4tetrahydroisoquinoline (ADTIQ) in parkinsonian brains," Journal of Neural Transmission, vol. 119, no. 4, pp. 435-441, 2012.

[151] D. A. D. Monte, “The environment and Parkinson's disease: is the nigrostriatal system preferentially targeted by neurotoxins?," The Lancet Neurology, vol. 2, no. 9, pp. 531-538, 2003.

[152] H. Vicente Miranda, O. M. A. El-Agnaf, and T. F. Outeiro, "Glycation in Parkinson's disease and Alzheimer's disease," Movement Disorders, vol. 31, no. 6, pp. 782-790, 2016.

[153] S. Meng, J. Cao, Q. He et al., "Metformin activates AMPactivated protein kinase by promoting formation of the $\alpha \beta \gamma$ HETEROTRIMERIC COMPLEX," Journal of Biological Chemistry, vol. 290, no. 6, pp. 3793-3802, 2014.

[154] C. J. Bailey and R. C. Turner, "Metformin," New England Journal of Medicine, vol. 334, no. 9, pp. 574-579, 1996.

[155] A. Martin-Montalvo, E. Mercken, S. Mitchell et al., "Metformin improves healthspan and lifespan in mice," Nature Communications, vol. 4, no. 1, p. 2129, 2013.

[156] J. Wang, D. Gallagher, L. M. DeVito et al., "Metformin activates an atypical PKC-CBP pathway to promote neurogenesis and enhance spatial memory formation," Cell Stem Cell, vol. 11, no. 1, pp. 23-35, 2012.

[157] M. Dulovic, M. Jovanovic, M. Xilouri et al., “The protective role of AMP-activated protein kinase in alpha-synuclein neurotoxicity in vitro," Neurobiology of Disease, vol. 63, pp. 1-11, 2014.

[158] F. M. Ashcroft and P. Rorsman, "KATP channels and islet hormone secretion: new insights and controversies," Nature Reviews Endocrinology, vol. 9, no. 11, pp. 660-669, 2013.

[159] D. R. Gehlert and D. W. Robertson, "ATP sensitive potassium channels: potential drug targets in neuropsychopharmacology," Progress in NeuroPsychopharmacology and Biological Psychiatry, vol. 18, no. 7, pp. 1093-1102, 1994.

[160] S. Wang, L.-f. Hu, Y. Yang, J.-h. Ding, and G. Hu, "Studies of ATP-sensitive potassium channels on 6-hydroxydopamine and haloperidol rat models of Parkinson's disease: Implications for treating Parkinson's disease?," Neuropharmacology, vol. 48, no. 7, pp. 984-992, 2005.

[161] J. A. Crestanello, N. M. Doliba, A. M. Babsky et al., “Opening of potassium channels protects mitochondrial function from calcium overload," Journal of Surgical Research, vol. 94, no. 2, pp. 116-123, 2000.

[162] A. L. Hevener, J. M. Olefsky, D. Reichart et al., "Macrophage $\operatorname{PPAR} \gamma$ is required for normal skeletal muscle and hepatic insulin sensitivity and full antidiabetic effects of thiazolidinediones," Journal of Clinical Investigation, vol. 117, no. 6, pp. 1658-1669, 2007.

[163] J. R. Colca, W. G. McDonald, D. J. Waldon et al., "Identification of a novel mitochondrial protein ("mitoNEET") cross-linked specifically by a thiazolidinedione photoprobe," American Journal of Physiology-Endocrinology and Metabolism, vol. 286, pp. 252-260, 2004.

[164] M. L. Paddock, S. E. Wiley, H. L. Axelrod et al., "MitoNEET is a uniquely folded $2 \mathrm{Fe} 2 \mathrm{~S}$ outer mitochondrial membrane protein stabilized by pioglitazone," Proceedings of the $\mathrm{Na}$ tional Academy of Sciences, vol. 104, no. 36, pp. 14342-14347, 2007.

[165] S. E. Wiley, M. L. Paddock, E. C. Abresch et al., "The outer mitochondrial membrane protein mitoNEET contains a novel redox-active $2 \mathrm{Fe}-2 \mathrm{~S}$ cluster," Journal of Biological Chemistry, vol. 282, no. 33, pp. 23745-23749, 2007.

[166] S. Ghosh, N. Patel, D. Rahn et al., "The thiazolidinedione pioglitazone alters mitochondrial function in human neuron-like cells," Molecular Pharmacology, vol. 71, no. 6, pp. 1695-1702, 2007.

[167] E. De Pablo-Fernández, D. P. Breen, P. M. Bouloux, R. A. Barker, T. Foltynie, and T. T. Warner, "Neuroendocrine abnormalities in Parkinson's disease," Journal of Neurology, Neurosurgery \& Psychiatry, vol. 88, no. 2, pp. 176-185, 2016.

[168] C. Hölscher, "Drugs developed for treatment of diabetes show protective effects in Alzheimer's and Parkinson's diseases," Sheng Li Xue Bao, vol. 66, pp. 497-510, 2014.

[169] D. Athauda and T. Foltynie, "Insulin resistance and Parkinson's disease: a new target for disease modification?," Progress in Neurobiology, vol. 145-146, pp. 98-120, 2016.

[170] D. Athauda, R. Wyse, P. Brundin, and T. Foltynie, "Is exenatide a treatment for Parkinson's disease?," Journal of Parkinson's Disease, vol. 7, no. 3, pp. 451-458, 2017.

[171] S. Efendic and N. Portwood, "Overview of incretin hormones," Hormone and Metabolic Research, vol. 36, no. 11/12, pp. 742-746, 2004.

[172] E. Matteucci and O. Giampietro, "Mechanisms of neurodegeration in type 2 diabetes and the neuroprotective potential of dipeptidyl peptidase 4 inhibitors," Current Medicinal Chemistry, vol. 22, no. 13, pp. 1573-1581, 2015.

[173] L. E. Ericson, R. Håkanson, and I. Lundquist, "Accumulation of dopamine in mouse pancreatic B-cells following injection of L-DOPA. Localization to secretory granules and inhibition of insulin secretion," Diabetologia, vol. 13, no. 2, pp. 117-124, 1977.

[174] F. Lopez Vicchi, G. M. Luque, B. Brie, J. P. Nogueira, I. Garcia Tornadu, and D. Becu-Villalobos, "Dopaminergic drugs in type 2 diabetes and glucose homeostasis," Pharmacological Research, vol. 109, pp. 74-80, 2016.

[175] I. Furigo, "Estudo do mecanismo de ação da bromocriptina e de antagonistas de prolactina no tratamento do Diabetes Mellitus tipo 2 e da obesidade," Instituto de Ciências Biomédicas, Universidade de São Paulo, São Paulo, Brazil, 2016, http://www.teses.usp.br/teses/disponiveis/42/42137/tde16052017-145647/pt-br.php. 


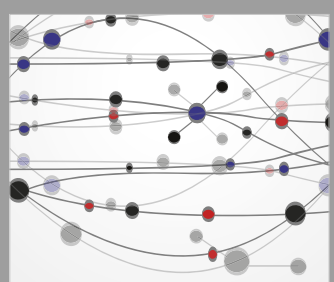

The Scientific World Journal
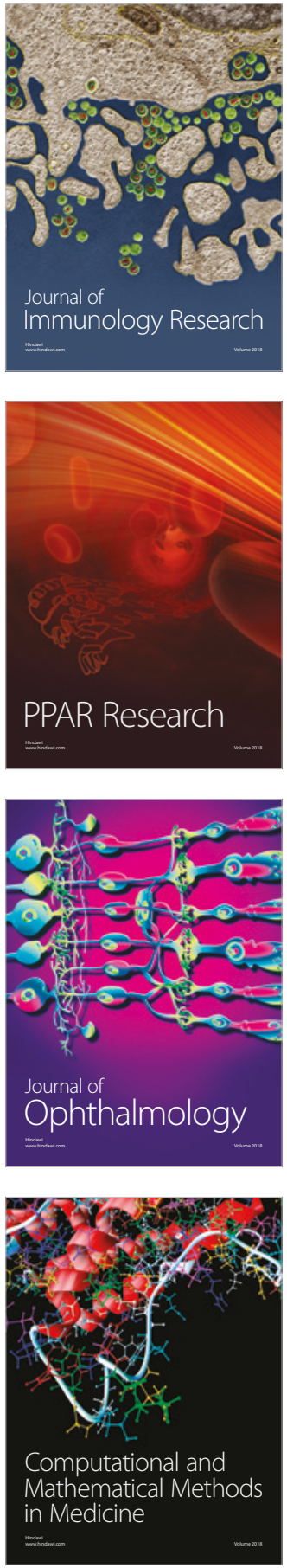

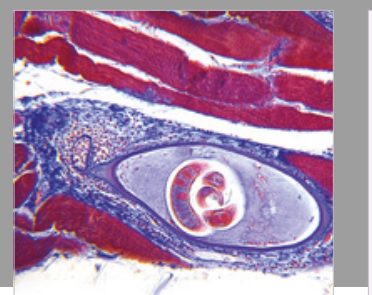

Gastroenterology Research and Practice

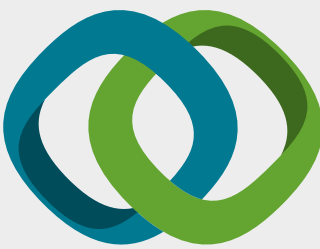

\section{Hindawi}

Submit your manuscripts at

www.hindawi.com
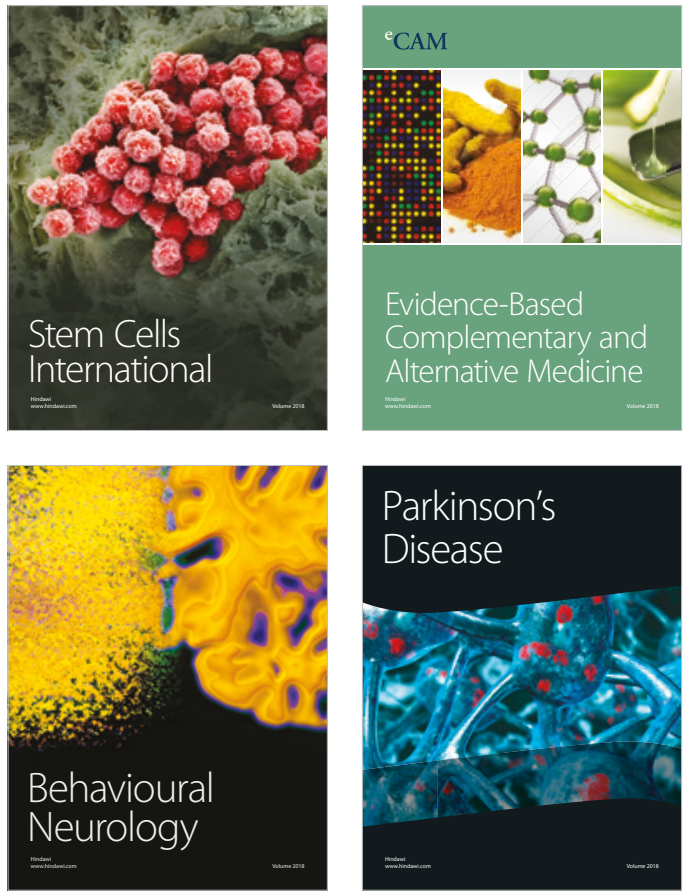

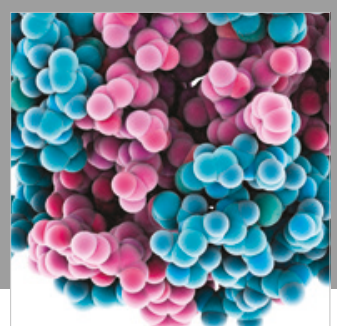

ournal of

Diabetes Research

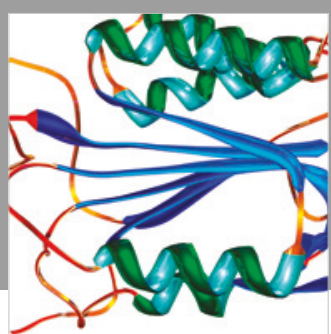

Disease Markers
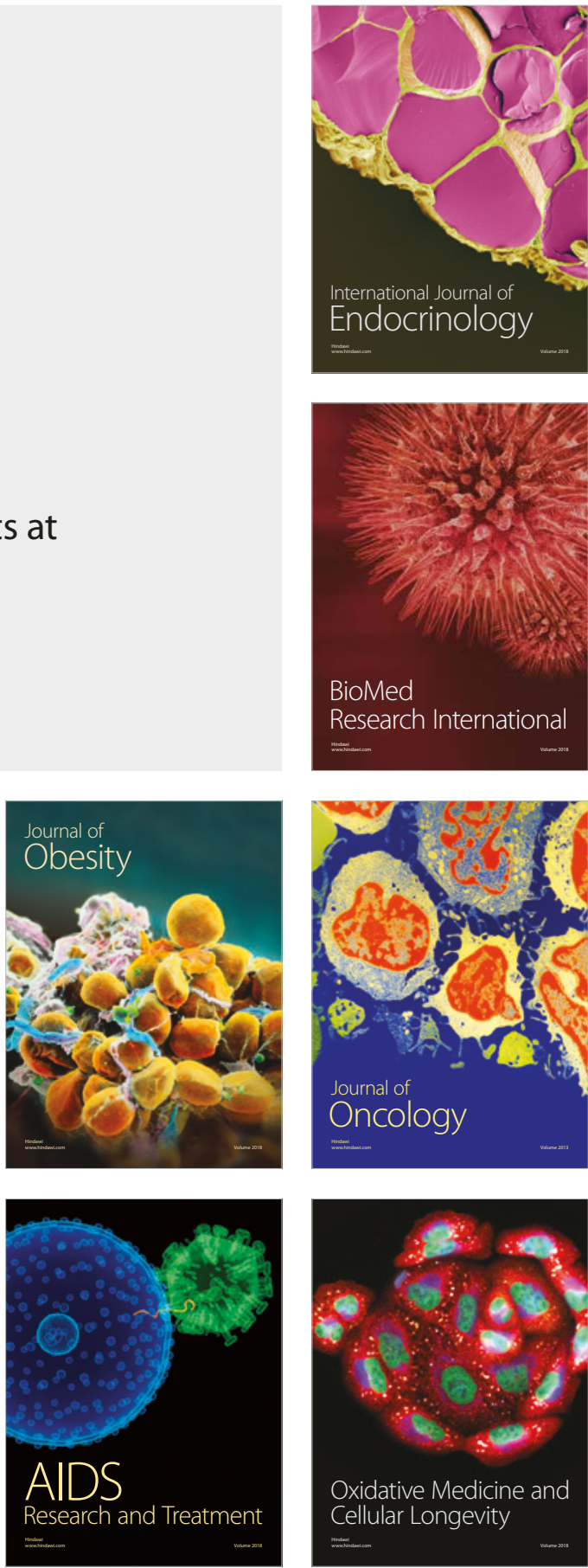